\title{
High appendicectomy rates in Ireland: why?
}

\author{
STEPHEN EA ATTWOOD, MARY T CAFFERKEY AND A BRIAN WEST \\ From Department of Surgery, the Adelaide Hospital, and Departments of Clinical Microbiology and Pathology, \\ Trinity College, Dublin
}

SUMMARY Age-specific appendicectomy rates for Ireland have recently been reported to be substantially higher than those for Scotland. We attempted to determine the reason for this difference. Records of 940 appendicectomies performed in one urban and one rural centre in Ireland over a 12 month period were examined to establish the frequency of acute appendicitis. Appendicitis rates were derived from these data. Appendicectomy rates are higher in Ireland because the incidence of acute appendicitis is greater than in Scotland or England and Wales and are not the result of variations in medical practice.

Age-specific appendicectomy rates derived from Hospital In-Patient Enquiry (HIPE) statistics for the Republic of Ireland are 1.5 to 2.0 times greater than comparable rates for Scotland' (see table). We attempted to determine whether these differences are due to variations in medical practice or to intrinsic differences in the incidence of acute appendicitis in the two countries.

Appendicectomy and appendicitis rates per 10000 population by age

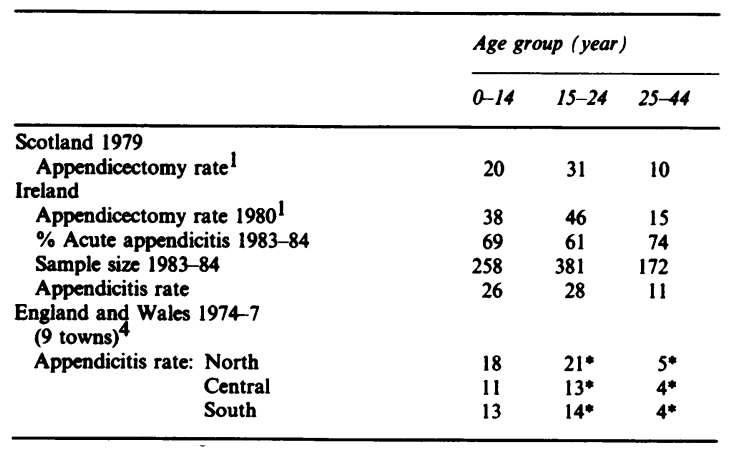

* Data for England and Wales ${ }^{4}$ are for age groups 0-14, 15-29, and over 29 years.

Methods

Records were obtained from 940 patients who underwent appendicectomy between 1 October 1983 and 30 September 1984. This sample comprised approximately $10 \%$ of all appendicectomies performed in Ireland during this period and included 467 consecutive cases from a rural centre (Tullamore General Hospital, Co. Offaly) and $\mathbf{4 7 3}$ from an urban population (Adelaide, Meath and St. James's Hospitals, Dublin). The ratio of urban to rural residents and the distribution of socioeconomic groups within the sample were thought to be representative of the Irish population. All appendices resected in the study hospitals were submitted for histology.

Incidental appendicectomies (44), which are excluded from HIPE statistics, were disregarded, but all primary appendicectomies were included. On the basis of pathology reports, each appendix was assigned one of four categories: I acute appendicitis in otherwise normal appendices. This was defined as the presence of mucosal or submucosal acute inflammation. It was almost always associated with ulceration and usually with neutrophil infiltration of the muscularis propria. II appendices with carcinoid tumour, primary or metastatic adenocarcinoma, cystadenoma, hyperplastic mucosal polyp, Crohn's disease or Enterobius vermicularis infestation, whether acutely inflamed or not. III non-inflamed appendices with severe lymphoid hyperplasia, spirochaetosis or luminal pus. IV histologically normal appendices, including those with mural fibrosis.

\section{Results}

The 896 primary appendicectomies included 596 $(67 \%)$ with acute appendicitis (category I), $41(5 \%)$ in category II, $11(1 \%)$ in category III, and $248(28 \%)$ normals (category IV). The proportion with histological acute appendicitis $(67 \%)$ is similar to that reported from the United States $(74 \%)^{2}$ and to figures estimated for one Scottish centre from data reported by Gunn $^{3}(62-76 \%)$.

Appendicitis rates have been calculated for each age group as the product of appendicectomy rate and $\%$ acute appendicitis (see table). Although the available primary data are from different years 
(appendicectomy rates for $1980,{ }^{1} \%$ acute appendicitis for 1983-4), we believe that they are typical. The calculated Irish appendicitis rate exceeds the Scottish appendicectomy rate in two age groups (0-14 and 25-44 years), and in the third almost equals it. Thus, even without knowing Scottish appendicitis rates, it is apparent that if our data are representative, the intrinsic incidence of acute appendicitis in Ireland exceeds that in Scotland, and the differences in appendicectomy rates between the two countries are not simply due to variation in practice.

Comparison of the Irish data with appendicitis rates prepared for selected centres in England and Wales (see table) reveals that, although only the 0-14 year age group is strictly comparable, and criteria for acute appendicitis in this study were slightly different, Irish appendicitis rates are higher than these also.

\section{Discussion}

Regional variations in appendicectomy rates have been attributed to variations in population structure, in medical practice, and in the incidence of acute appendicitis. Our results suggest that the differences in appendicectomy rates between Ireland and Britain are due principally to a higher incidence of acute appendicitis in Ireland. If our estimates for the overall population are correct, it seems probable that regional analysis in Ireland would lead to identification of areas with an even greater incidence. These could be of special value in investigating the roles of infections, ${ }^{5}$ diet, ${ }^{6}$ and other agents tentatively implicated in the aetiology of acute appendicitis.

We thank Dr $R$ Hamill, of the Medico-Social Research Board, for helpful discussions, $\mathrm{Dr} \mathbf{K}$ Cunnane and Dr D Gilsenan for allowing us use of the Tullamore records, Ms R Brougham for accessing them, and Ms B Doyle and Ms D O'Reilly for typing the manuscript.

Correspondence and reprint requests to: $\mathrm{Dr} A B$ West, Department of Pathology, Yale University School of Medicine, 310 Cedar Street, New Haven, CT 06510, USA.

\section{References}

'Medico-Social Research Board of Ireland, Annual Report for 1983 Dublin, 1984:24-6.

${ }^{2}$ Butler C. Surgical pathology of acute appendicitis. Hum Pathol 1981; 12: 870-8.

${ }^{3}$ Gunn AA. The diagnosis of acute abdominal pain with computer analysis. JR Coll Surg Ed 1976; 21: 170-2.

${ }^{4}$ Barker DJP, Liggins A. Acute appendicitis in nine British towns. Br Med J 1981; 283: 1083-5.

${ }^{5}$ Barker DJP. Acute appendicitis and dietary fibre: an alternative hypothesis. $\mathrm{Br}$ Med J 1985; 290: 1125-7.

- Barker DJP, Morris J, Nelson M. Vegetable consumption and acute appendicitis in 59 areas in England and Wales. Br Med J 1986; 292: 927-30. 